\title{
Vanillin acrylate-based thermo-responsive shape memory antimicrobial photopolymers
}

\author{
Aukse Navaruckiene $e^{(0}$, Danguole Bridziuviene ${ }^{2(0}$, Vita Raudoniene ${ }^{2(0}$, Egidija Rainosalo $^{3(0)}$, \\ Jolita Ostrauskaite ${ }^{1 * \mathbb{C}}$ \\ ${ }^{1}$ Department of Polymer Chemistry and Technology, Kaunas University of Technology, Radvilenu Rd. 19, LT-50254 \\ Kaunas, Lithuania \\ ${ }^{2}$ Biodeterioration Research Laboratory, Nature Research Center, Akademijos Str. 2, LT-08412 Vilnius, Lithuania \\ ${ }^{3}$ Centria University of Applied Sciences, Talonpojankatu 2, FI-67100 Kokkola, Finland
}

Received 29 July 2021; accepted in revised form 22 October 2021

\begin{abstract}
Vanillin acrylate-based thermo-responsive shape memory photopolymers with high thermal stability, tunable mechanical properties, and antimicrobial activity have been developed. Photocurable resins containing one of the three commercial vanillin derivatives, vanillin diacrylate, vanillin dimethacrylate, and vanillin hydroxypropane dimethacrylate, and 1,3-benzenedithiol were tested. The results of dual curing systems with different ratios of thiol and acrylate (1:1 and $0.5: 1)$ were compared. The reduction of thiol content increased the rate of photocuring, improved the mechanical performance of polymers (Young's modulus was increased from 1.4-3.5 to 3952.3-11339.4 MPa), and their heat resistance (the $10 \%$ weight loss increased from $277-327$ to $294-341^{\circ} \mathrm{C}$ ). All polymers were able to return to their primary shape after deformation and maintain their temporary shape at a temperature lower than their glass transition temperature $\left(-3-46^{\circ} \mathrm{C}\right)$. Furthermore, allpolymer films exhibited significant antibacterial activity against Escherichia coli and Staphylococcus aureus (cell reduction reached $99.8-100 \%$ after $24 \mathrm{~h}$ ) and antifungal activity against Aspergillus flavus and Aspergillus niger (cell reduction reached $72.3-100 \%$ after $24 \mathrm{~h})$.
\end{abstract}

Keywords: thermosetting resins, photopolymerization, dual-curing, shape memory, antimicrobial activity

\section{Introduction}

Recently, shape memory polymers have received much attention due to their unique ability to obtain temporary shapes and return to their permanent shape in response to stimulus [1]. These polymers have a wide application area, such as intelligent medical devices, heat-shrinkable tubes for electronics [2], aerospace applications, and self-healing materials [3]. Nowadays, technologies are an integral part of everyday life, and the need for smart materials is growing rapidly [4], leading to the increasing interest in new bio-based shape memory polymers suitable for future applications in the fast-growing field of smart materials [5].
Bio-based materials attract the interest of the scientific community as an ecological and economical alternative to petrochemical-based materials [6]. Bio-based high-performance materials are becoming a major trend in the research and development of shape memory polymers [7]. The typical characteristics of high-performance polymers are high mechanical strength and high heat resistance [8]. In recent years, new bio-based shape-memory polymers have been synthesized from plant-derived materials by thermal polymerization. Only a few biobased shape memory polymers have been prepared by UV photopolymerization [9]. However, most bio-based shape memory polymers have low glass 
transition temperatures, which limits their applications [7].

Antimicrobial shape-memory materials are attracting a lot of attention in biomedical applications [10], e.g., bone scaffolding [11]. For example, a self-healable conductive polyurethane with shape memory and antimicrobial properties has been synthesized and shown to be suitable for use as a bone scaffold [12]. Antimicrobial shape memory composites have been developed by combining synthetic polymers possessing shape memory properties and natural polymers [13]. However, most antimicrobial materials that possess shape memory properties are not bio-based. To fill this gap, this study focused on developing novel bio-based antimicrobial shape memory polymers using vanillin derivatives.

Approximately $20 \%$ of vanillin is produced from natural sources. It can be extracted directly from plants, such as vanilla orchid beans or produced by the chemical modification of lignin. Lignin is the main source of plant-derived vanillin [14]. In the last years, vanillin and its derivatives have been used in polymer synthesis because their aromatic structure provides polymers with high rigidity and thermal stability [15]. Hydroxyl and aldehyde groups present in vanillin can be modified, and new derivatives might be used as monomers for polymerization [16]. Vanillin demonstrates high antibacterial activity that leads to its extensive use in food packaging or medicine [17]. Both thermal polymerization $[18,19]$ and photopolymerization [20] have been used for polymer synthesis from vanillin derivatives. Vanillin methacrylate was successfully copolymerized with acrylate epoxidized soybean oil. The mechanical properties of these polymers were improved by increasing the amount of vanillin methacrylate fragments in the polymer [19]. Vanillin methacrylate and vanillin dimethacrylate were also used in radical polymerization. The polymers obtained demonstrated high thermal stability and had a huge potential in the production of polymer composites [18]. Vanillin acrylate has also been used in radical polymerization. Vanillin acrylate-based polymers were stiff materials with a high glass transition temperature (up to $168^{\circ} \mathrm{C}$ ) and could be used as organic coatings [19]. Recently, the use of vanillin for the synthesis of renewable polymers has attracted a lot of interest as it is one of the commercially available bio-based aromatic compounds [21]. However, none of these studies focused on the use of vanillin derivatives in dual curing systems or in the production of shape memory polymers. In this study, for the first time, the photocuring kinetics of vanillin acrylate-based dual curing systems and mechanical, thermal, and antimicrobial properties of the resulting polymers have been investigated.

Dual curing is one of the possible ways to obtain shape-memory materials. The combination of two simultaneous or sequential curing reactions [22] results in the formation of interpenetrating or semi-interpenetrating polymer networks [23]. This allows the development of materials with unique thermal and mechanical properties that could not be obtained using other polymerization reactions [24, 25]. Dualcured thermosets were successfully prepared using off-stoichiometric formulations of thiol-acrylate systems [26]. The resulting materials display a wide range of properties [27] and are easily adaptable to a wide variety of applications, such as shape-memory polymers, optical materials, protective coatings, photolithography, holographic materials, etc. [28].

In this work, commercial vanillin acrylates were selected with the aim of finding efficient photocurable systems suitable for industrial application in environmentally friendly light-based additive manufacturing technologies. Three vanillin derivatives, vanillin diacrylate (VD), vanillin dimethacrylate (VDM), and vanillin hydroxypropane dimethacrylate (VHDM), were tested in photopolymerization with 1,3-benzenedithiol (BDT). By varying the ratio of acrylate to thiol (from 1:1 to 1:0.5), the rate of thiol-acrylate photopolymerization and free-radical photopolymerization was tuned, and polymers possessing different mechanical and thermal properties were obtained. Ethyl(2,4,6-trimethylbenzoyl)phenylphosphinate (TPOL) was selected as the photoinitiator, as it is preferred due to the photobleaching effect that provides transparent coatings and allows the lower layers of the coating to cure [29]. Real-time photorheometry was used to monitor the photocuring kinetics, rheological parameters, and shrinkage, as these parameters have a significant impact on the application of polymer resins. The yield of insoluble fraction and swelling value of the polymers were calculated to confirm their crosslinked structure. The thermal and mechanical properties were investigated and compared with those of other acrylate-based photopolymers [30]. Also, the antibacterial and antifungal properties of the polymer films were investigated as well. All of the properties mentioned above enable the wide use of vanillin-based antimicrobial shape 
memory polymers in a huge variety of applications, including smart materials.

\section{Experimental}

\subsection{Materials}

Vanillin diacrylate (VD), vanillin dimethacrylate (VDM), and vanillin hydroxypropane dimethacrylate (VHDM) (all from Specific Polymers), 1,3-benzenedithiol (BDT), ethyl(2,4,6-trimethylbenzoyl) phenylphosphinate (TPOL, Fluorochem) (Figure 1), tetrahydrofurane (THF, Eurochemicals), chitosan and hydroxyethyl starch (both from Sigma-Aldrich) were used as received.

\subsection{Preparation of crosslinked polymer specimens}

The mixtures containing $1 \mathrm{~mol}$ of vanillin derivative (VD, VDM or VHDM), $3 \mathrm{~mol} \%$ of TPOL, 1 or $0.5 \mathrm{~mol}$ of BDT were stirred with a magnetic stirrer at room temperature $\left(25^{\circ} \mathrm{C}\right)$ for $1 \mathrm{~min}$. VDM was dissolved in small volume of THF before mixing with other resin components $(0.2 \mathrm{ml}$ of THF for $1 \mathrm{~g}$ of

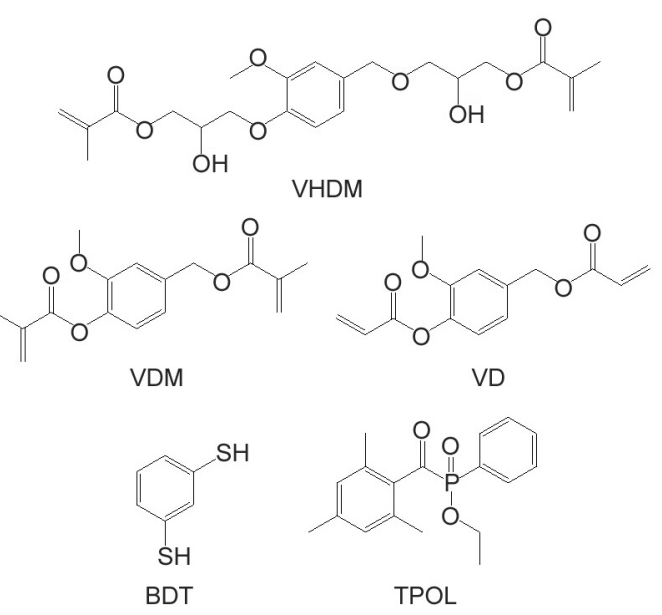

Figure 1. Chemical structure of vanillin hydroxypropane dimethacrylate (VHDM), vanillin dimethacrylate (VDM), vanillin diacrylate (VD), 1,3-benzenedithiol (BDT) and ethyl(2,4,6-trimethylbenzoyl) phenylphosphinate (TPOL).
VDM). When homogenous mixtures were obtained, the resins were poured into a Teflon mold and cured for 2-5 min under a UV/Vis lamp (Helios Italquartz, model GR.E $500 \mathrm{~W}$, Milan, Italy) with an intensity of $310 \mathrm{~mW} / \mathrm{cm}^{2}$. The composition of the resins is presented in Table 1.

\subsection{Characterization techniques}

Fourier transformation infrared spectroscopy (FTIR) spectra were recorded using a Spectrum BX II FT-IR spectrometer (Perkin Elmer, Llantrisant, UK) in the range of $650-4000 \mathrm{~cm}^{-1}$. Reflection was measured during the test.

The Soxhlet extraction was used to determine the yield of the insoluble fraction. Polymer samples of $0.3 \mathrm{~g}$ were extracted with acetone for $24 \mathrm{~h}$. After $24 \mathrm{~h}$, the insoluble fractions were dried under vacuum until no change in mass was observed. The yield of the insoluble fraction was calculated as the difference in mass before and after the extraction and drying.

The swelling values of the crosslinked polymer specimens were obtained by measuring the mass of specimens swollen in acetone at $25^{\circ} \mathrm{C}$. Polymer film specimens of $20 \pm 0.1 \mathrm{~mm}$ length, $9 \pm 0.05 \mathrm{~mm}$ width, and $1 \pm 0.05 \mathrm{~mm}$ thickness were used. The change of mass was measured every $10 \mathrm{~min}$ and the percentage change in mass was calculated.

Differential scanning calorimetry (DSC) measurements were performed on a DSC 8500 apparatus (Perkin Elmer, Llantrisant, UK). The heating rate of $20^{\circ} \mathrm{C} / \mathrm{min}$ under nitrogen atmosphere $(50 \mathrm{ml} / \mathrm{min})$ and the temperature range of $-40-110^{\circ} \mathrm{C}$ of the heating-cooling-heating cycle were used. Hermetic aluminum pans were used. The glass transition temperature was calculated as a midpoint of the glass transition step of the second heating curve using the TA Universal Analysis software.

Thermogravimetric analysis (TGA) was performed on a TGA 4000 apparatus (Perkin Elmer, Llantrisant, UK). A heating rate of $20^{\circ} \mathrm{C} / \mathrm{min}$ under a nitrogen

Table 1. Composition of resins C1-C6.

\begin{tabular}{|c|c|c|c|c|c|}
\hline Resin & $\begin{array}{c}\text { Vanillin } \\
\text { derivative }\end{array}$ & $\begin{array}{c}\text { Amount of vanillin } \\
\text { derivative } \\
\text { [mol] }\end{array}$ & $\begin{array}{c}\text { Amount of 1,3- } \\
\text { benzenedithiol } \\
\text { [mol] }\end{array}$ & $\begin{array}{c}\text { Amount of the } \\
\text { photoinitiator TPOL } \\
\text { [mol\%] }\end{array}$ & Solvent \\
\hline C1 & VD & 1 & 1.0 & 3 & - \\
\hline C2 & VD & 1 & 0.5 & 3 & - \\
\hline C3 & VDM & 1 & 1.0 & 3 & THF \\
\hline C4 & VDM & 1 & 0.5 & 3 & THF \\
\hline C5 & VHDM & 1 & 1.0 & 3 & - \\
\hline C6 & VHDM & 1 & 0.5 & 3 & - \\
\hline
\end{tabular}


atmosphere $(100 \mathrm{ml} / \mathrm{min})$ was chosen. The temperature range of $10-800^{\circ} \mathrm{C}$ was used. Aluminum oxide pans were used.

Measurement of the temperature at which the material starts to soften under compression load was carried out on an MCR302 rheometer (Anton Paar, Graz, Austria) in the temperature range from -40 to $60^{\circ} \mathrm{C}$ with a heating rate of $2{ }^{\circ} \mathrm{C} / \mathrm{min}$. The thickness of specimens was $1.0 \pm 0.15 \mathrm{~mm} .8 \mathrm{~mm}$ diameter flat end road was used to apply the load. The maximum load was $5 \mathrm{~N}$ applied with a frequency of $1 \mathrm{~Hz}$.

The mechanical properties of the synthesized polymers were determined by the tensile test, which was performed on a Testometric M500-50CT testing machine (Testometric Co Ltd, Rochdale, UK) with flatface grips at room temperature $\left(25^{\circ} \mathrm{C}\right)$. The dimensions of the test specimens were $50 \pm 0.00 \times 10 \pm 0.00 \times$ $1 \pm 0.15 \mathrm{~mm}$. The gap between the grips was set to $20 \mathrm{~mm}$, and a test was performed at the speed of $5 \mathrm{~mm} / \mathrm{min}$ until the specimen broke. Young's modulus, tensile strength, and elongation at break were determined.

Statistical analysis. The collected data were statistically analyzed using ANOVA for the Microsoft Excel program. All experiments were carried out in triplicate, except for the tensile test in which five replicates were used, and the results are presented as the average values \pm standard deviation. The estimated $p$-value was below 0.05 within the groups.

\subsection{Real-time photorheometry}

$\mathrm{UV} /$ Vis curing tests were performed with vanillin acrylate-based resins containing $1 \mathrm{~mol}$ of acrylate (VD, VDM, or VHDM), 1 or $0.5 \mathrm{~mol}$ of BDT, $3 \mathrm{~mol} \%$ of TPOL, and a small amount of THF (only in VDM-based resins) on an MCR302 rheometer (Anton Paar, Graz, Austria) equipped with the plate/ plate measuring system. The Peltier-controlled temperature chamber with the glass plate (diameter was $38 \mathrm{~mm}$ ) and the top plate PP15 (diameter was $15 \mathrm{~mm}$ ) was used. The measurement gap was set to $0.1 \mathrm{~mm}$, and the samples were irradiated with UV/Vis light in a wavelength range of $250-450 \mathrm{~nm}$ through the glass plate using the UV/Vis spot curing system OmniCure S2000 (Lumen Dynamics Group Inc., Mississauga, ON, Canada). The temperature was $25^{\circ} \mathrm{C}$. In all cases, a shear mode with a frequency of $10 \mathrm{~Hz}$ and a shear strain of $1 \%$ was used. The storage modulus $\left(G^{\prime}\right)$, the loss modulus $\left(G^{\prime \prime}\right)$, the loss factor $(\tan \delta)$, and the complex viscosity $\left(\eta^{*}\right)$ were recorded as a function of the irradiation time. Values for each parameter were collected every 1 second, of 125 points per 125 seconds of photocuring. The gel point $\left(t_{\mathrm{gel}}\right)$ indicated the formation of the polymeric network and was calculated as the intersection point of $G^{\prime}$ and $G^{\prime \prime}$. The shrinkage was calculated from the reduction of the height of sample during the polymerization process. The normal force was set to $0 \mathrm{~N}$ during the measurement of sample shrinkage. The mean value and standard deviation were obtained from five measurements of each resin.

\subsection{Antimicrobial test}

The study of the antimicrobial (antibacterial and antifungal) activity of polymers was performed using two strains of bacteria, Gram-negative bacteria $E s$ cherichia coli ATCC 25922 (E. coli) and Gram-positive bacteria Staphylococcus aureus ATCC 29213 (S. aureus), and two fungal strains, Aspergillus niger 0999-14 (A. niger) and Aspergillus flavus 1087-03 (A. flavus). Microorganism suspensions were prepared from fully mature cultures. The concentration of suspensions was determined by measuring the optical density with a spectrophotometer (Evolution 60S, Thermo Fisher Scientific, Waltham, MA, USA) and then was corrected by plating on nutrient media. The final inoculum concentrations were $7.6 \cdot 10^{6}$ for E. coli, $4.7 \cdot 10^{6}$ for $S$. aureus, $2.6 \cdot 10^{6}$ for $A$. niger, and $1.66 \cdot 10^{6}$ colony-forming units $/ \mathrm{ml}[\mathrm{CFU} / \mathrm{ml}]$ for A. flavus. The test films $(10 \times 10 \mathrm{~mm})$ were placed in empty Petri dishes. Then $10 \mu \mathrm{l}$ of the bacterial or fungal suspension was applied to their surface. For comparison, chitosan and hydroxyethyl starch films were infected in the same manner. Plates with infected films were incubated for $24 \mathrm{~h}$ in a humid chamber ( $90 \%$ relative humidity) at $37^{\circ} \mathrm{C}$ in the case of infection with bacteria and at $26^{\circ} \mathrm{C}$ in the case of infection with the fungi. After 2, 6, and $24 \mathrm{~h}$ of incubation, $2 \mathrm{ml}$ of saline was applied to each film to remove the spores. The resulting suspensions were seeded on nutrient media (bacteria on Mueller Hinton Agar (MHA, Liofilmchem, Italy) and microscopic fungi on Malt Extract Agar (MEA, Liofilmchem, Italy)) and incubated at $37^{\circ} \mathrm{C}$ with bacteria and $26^{\circ} \mathrm{C}$ with fungi. After 1-2 days of incubation, the grown bacterial colonies were counted, whereas the fungal colonies were counted after 5-6 days. The percentage reduction was calculated according to the formula: $(a-b) / a \cdot 100 \%$, and the $\lg$ reduction of viable spores was calculated according to the formula: 
$\lg a-\lg b$, where $a$ is the concentration of the colonyforming units $[\mathrm{CFU} / \mathrm{ml}]$ in inoculum suspension; $b$ is a mean of viable spores [CFU $/ \mathrm{ml}$ ] on specimens from triplicate experiments after incubation.

\section{Results and discussions}

\subsection{Monitoring of photocuring kinetics by real-time photorheometry}

The photocuring of vanillin acrylate-based resins was studied by real-time photorheometry. The reaction speed (described by $t_{\mathrm{gel}}$, induction period and slope of the curve) is the limiting factor in applications requiring fast polymerization and crosslinking. For example, in optical 3D printing, a lower value of $t_{\text {gel }}$ can increase the speed of the printing process from hours to minutes as the models are composed of different layers. All of these layers require their individual time to polymerize, which results in a long process when resins with high $t_{\text {gel }}$ values are used [31]. Shrinkage is the second important parameter for optical 3D printing and other applications of polymers. High shrinkage values can limit the preparation of final products from resins as they make it hard to obtain the desired size [32]. The rigidity of polymers is important in their final application; however, both soft and flexible polymers and hard and rigid polymers are used in different areas of application. In this study, real-time photorheometry was used to monitor the storage modulus $G^{\prime}$ which characterizes the rigidity of the formed polymers and shrinkage, which characterizes the volume loss [\%] during the photocuring process [33]. The real-time photorheometry data for all resins are summarized in Table 2. The dependencies of the storage modulus $G^{\prime}$, the loss modulus $G^{\prime \prime}$, loss factor tan $\delta$, and complex viscosity $\eta^{*}$ of the resin $\mathbf{C} \mathbf{9}$ on irradiation time are presented in Figure 2.

The dependence of the storage modulus $G^{\prime}$ on irradiation time of all vanillin-based resins is presented in Figure 3. As seen from the comparison of the

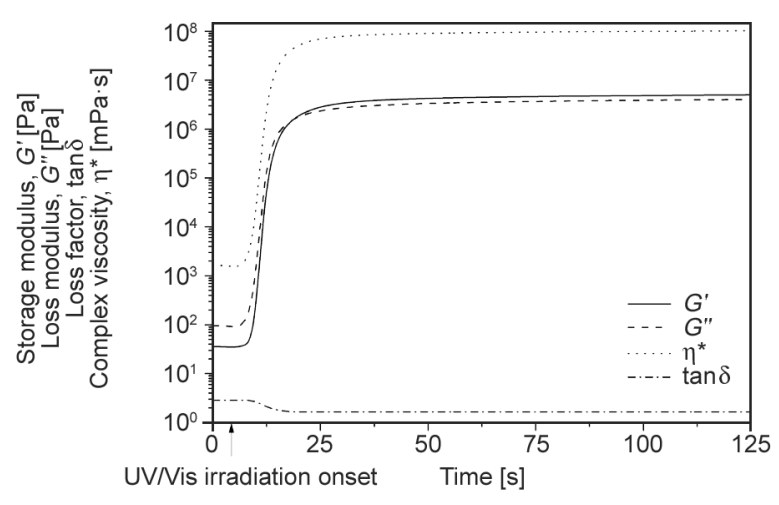

Figure 2. Dependencies of storage modulus $G^{\prime}$, loss modulus $G^{\prime \prime}$, loss factor $\tan \delta$, and complex viscosity $\eta^{*}$ of resin $\mathbf{C} \mathbf{9}$ on irradiation time.

shape of the $G^{\prime}$ curves of all resins and the data from Table 1, the highest final rigidity was demonstrated by dual-cured polymers with $1 \mathrm{~mol}$ of vanillin derivative (VD, VDM, or VHDM) and $0.5 \mathrm{~mol}$ of thiol (BDT) compared to polymers with $1 \mathrm{~mol}$ of thiol (BDT). The radical homopolymerization of acrylates became dominant in the dual-curing system, combining free-radical and thiol-acrylate photopolymerization in a higher ratio of acrylate to thiol [34]. Another advantage of the dominant radical homopolymerization of acrylates was the increase in the rate of photocuring. In all cases $(\mathbf{C} 2, \mathbf{C} 4, \mathbf{C 6})$, the $t_{\text {gel }}$ was reached faster when $0.5 \mathrm{~mol}$ of thiol was used. For example, $\mathbf{C 5}$ reached the gel point at $4.8 \mathrm{~s}$ and the rigidity of $5.47 \mathrm{MPa}$, while $\mathbf{C 6}$ reached the gel point at $3.4 \mathrm{~s}$ and the rigidity of $14.92 \mathrm{MPa}$.

The induction period, measured as the onset of the $G^{\prime}$ increase, of polymers prepared with $0.5 \mathrm{~mol}$ of thiol was also shorter than that of polymers prepared with 1 mol of thiol. After the onset of UV irradiation, $G^{\prime}$ of polymers with $0.5 \mathrm{~mol}$ of thiol increased rapidly with as little as a 1 second induction period, and the curve reached the plateau faster than that of polymers with $1 \mathrm{~mol}$ of thiol. The induction period of VD and VHDM-based polymers with 0.5 mol thiol was the same; only VDM-based polymer $\mathbf{C} 4$ had a slightly

Table 2. Rheological characteristics of vanillin acrylate-based resins.

\begin{tabular}{|c|c|c|c|c|c|c|}
\hline Resin & $\begin{array}{c}\text { Storage modulus, } \boldsymbol{G}^{\prime} \\
{[\mathbf{M P a}]}\end{array}$ & $\begin{array}{c}\text { Loss modulus, } \boldsymbol{G}^{\mathbf{\prime}} \\
{[\mathbf{M P a}]}\end{array}$ & Loss factor, tan $\boldsymbol{\delta}$ & $\begin{array}{c}\text { Complex viscosity, } \boldsymbol{\eta}^{*} \\
{[\mathbf{M P a} \cdot \mathbf{s}]}\end{array}$ & $\begin{array}{c}\text { Gel point, } \boldsymbol{t}_{\text {gel }} \\
{[\mathbf{s}]}\end{array}$ & $\begin{array}{c}\text { Shrinkage } \\
{[\%]}\end{array}$ \\
\hline $\mathbf{C 1}$ & $8.89 \pm 0.67$ & $2.37 \pm 0.71$ & $0.35 \pm 0.02$ & $0.149 \pm 0.001$ & $6.2 \pm 0.10$ & $5.75 \pm 0.50$ \\
\hline $\mathbf{C 2}$ & $11.14 \pm 0.61$ & $2.96 \pm 0.05$ & $0.21 \pm 0.01$ & $0.181 \pm 0.027$ & $4.8 \pm 0.10$ & $7.25 \pm 0.50$ \\
\hline C3 & $0.59 \pm 0.06$ & $0.30 \pm 0.01$ & $0.51 \pm 0.04$ & $0.011 \pm 0.001$ & $6.4 \pm 0.00$ & $4.00 \pm 0.00$ \\
\hline C4 & $10.52 \pm 0.12$ & $1.56 \pm 0.16$ & $0.15 \pm 0.01$ & $0.169 \pm 0.001$ & $5.2 \pm 0.00$ & $8.00 \pm 0.00$ \\
\hline C5 & $5.47 \pm 0.61$ & $4.15 \pm 0.05$ & $0.76 \pm 0.05$ & $0.109 \pm 0.001$ & $4.8 \pm 0.00$ & $4.00 \pm 0.00$ \\
\hline C6 & $14.92 \pm 0.16$ & $5.01 \pm 0.72$ & $0.34 \pm 0.02$ & $0.250 \pm 0.031$ & $3.4 \pm 0.10$ & $6.50 \pm 0.58$ \\
\hline
\end{tabular}


longer induction period due to the action of THF as a chain transfer agent that slows the photocuring process [35]. Polymers prepared with $1 \mathrm{~mol}$ of thiol had an induction period similar for all acrylates and a slightly longer induction period than polymers prepared with $0.5 \mathrm{~mol}$ of thiol. The $G^{\prime}$ curves were not so steep for these polymers and reached the plateau slower than for polymers with $0.5 \mathrm{~mol}$ thiol. These parameters have indicated that photopolymerization of resins with $1 \mathrm{~mol}$ thiol is a slower process [36].

Resins for various applications are required to have low shrinkage values or no shrinkage at all during the polymerization process, as it is one of the key parameters for high-quality final product [37]. It was determined that all polymers, prepared with $0.5 \mathrm{~mol}$ of thiol, shrunk more than those prepared with 1 mole of thiol. The higher shrinkage is the result of the freeradical photopolymerization of acrylates, one of two reactions that take place during the dual curing process [34]. Acrylates have a tendency to shrink during the polymerization process because long-distance connections through weak van der Waals forces are replaced by short, strong covalent bonds between carbon atoms in monomer units [37]. In this case, the use of the higher amount of thiol has the advantage of reducing the shrinkage during the photocuring process by lowering the amount of acrylate in the resin and the resulting polymer. For example, the double amount of thiol in VDM-based resin lowered the shrinkage twice, from $8 \%(\mathbf{C} 4)$ when $0.5 \mathrm{~mol}$ of thiol were used to $4 \%$ (C3) when $1 \mathrm{~mol}$ of thiol was used. The structure of the vanillin derivative also had an influence on photocuring kinetics and the value of shrinkage of the resulted polymers. For resins prepared with $0.5 \mathrm{~mol}$ of thiol, the lowest rigidity and the highest gel point value were shown by VDMbased resin with THF $(\mathbf{C} 3)$, and the resulted polymer shrunk most of all polymers. The photocuring induction period of the VDM-based resin was also higher than that of the VD- and VHDM-based resins. This can be explained by the action of THF as a chain transfer agent that slows the photocuring process [35]. The VD-based resin with $0.5 \mathrm{~mol}$ of thiol demonstrated similar results to the VDM-based resin; although $\mathbf{C} 2$ resin was slightly more rigid, it reached the gel point faster and shrunk less lightly than the VDM-based one. The explanation for these results is the different reactivity of the acrylate and methacrylate groups. Methacrylates are less reactive than acrylates as tertiary methacrylate radicals are highly stable compared to unstable secondary acrylate radicals [38]. Despite that, the VD-based polymer with $0.5 \mathrm{~mol}$ of thiol reached the plateau slightly slower than other resins with $0.5 \mathrm{~mol}$ of thiol. That indicated that the photopolymerization slowed down at the end. This can be explained by the darker color of vanillin diacrylate, which makes it harder to cure the deeper layers of the resin and slows the photopolymerization [39]. The best results among all resins, prepared with $0.5 \mathrm{~mol}$ of thiol, were demonstrated by the VHDMbased resin C6, which was the most rigid, had the lowest value of $t_{\text {gel, }}$, and shrunk the least. The chemical structure of VHDM is the reason for these results. VHDM is a longer molecule in comparison with VD and VDM, and the reaction rate increases linearly by increasing the distance between polymerizable groups in the polymerization process [40].

Similar results were obtained by comparing resins obtained from different vanillin derivatives and $1 \mathrm{~mol}$ of thiol. The only difference was the rigidity of VD- and VHDM-based polymers. The VD-based polymer $\mathbf{C 1}$ was more rigid than the VHDM-based polymer C5. This difference could be due to the high amount of thiol radicals formed in the initiation stage of polymerization when $1 \mathrm{~mol}$ of thiol was used. That led to the formation of many different polymer chains of different lengths with flexible thioether linkages, resulting in a lower rigidity of the obtained polymers [41]. The VHDM-based polymer formed a large number of polymeric chains with longer distances between the linkages in the presence of $1 \mathrm{~mol}$ of thiol compared to the VD-based polymer, which resulted

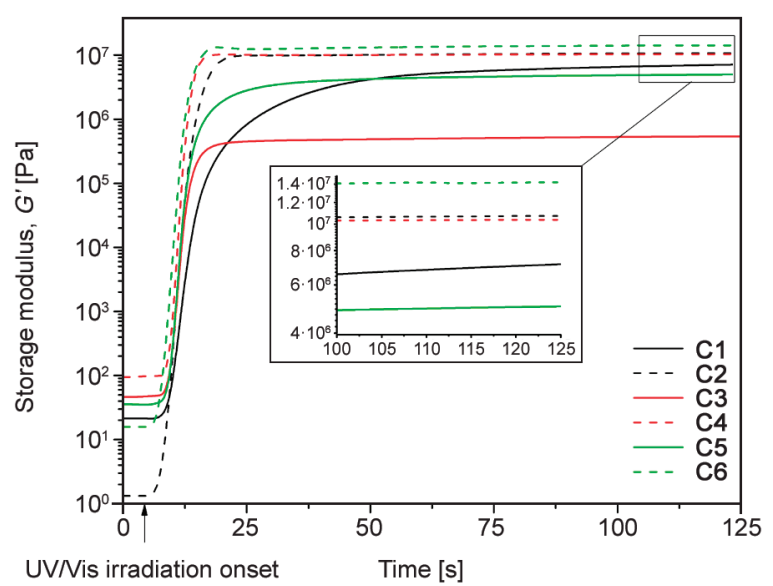

Figure 3. Dependency of storage modulus $G^{\prime}$ of the resins on irradiation time. - VD-based resins, - VDMbased resins, - VHDM-based resins, solid line presence of $1 \mathrm{~mol}$ of BDT, split line - presence of $0.5 \mathrm{~mol}$ of BDT. 
in lower rigidity of polymer $\mathbf{C 5}$. These results were confirmed by the higher swelling values of this polymer.

\subsection{Characterization of photocross-linked polymer structure}

The chemical structure of the vanillin-based polymers was identified by FT-IR spectroscopy. The intensity of the signals attributed to the $\mathrm{C}=\mathrm{C}$ group, which were present at $1607 \mathrm{~cm}^{-1}$, and the signals of the $\mathrm{C}=\mathrm{O}$ group, which were present at $1730 \mathrm{~cm}^{-1}$, in the FT-IR spectra of VD, VDM, and VHDM, were reduced in their polymer spectra. The signal of the $\mathrm{S}-\mathrm{H}$ group, which was present at $2,561 \mathrm{~cm}^{-1}$ in the spectrum of BDT, was weaker in the spectra of the polymers with $1 \mathrm{~mol}$ of thiol, and the signal of the $\mathrm{C}-\mathrm{S}$ group was observed at $1153-1119 \mathrm{~cm}^{-1}$ indicated the formation of polymers. The S-H group signal is absent in the spectra of the polymers with $0.5 \mathrm{~mol}$ of thiol, indicating that all $\mathrm{S}-\mathrm{H}$ groups reacted to form a polymer network. A weak signal of $\mathrm{C}=\mathrm{C}$ groups is present in the FT-IR spectra of all polymers, indicating that a small amount of unreacted acryl groups is left in the polymers. As an example, the FT-IR spectra of VHDM, BDT, and the crosslinked polymers $\mathbf{C 5}$ and $\mathbf{C 6}$ are presented in Figure 4.

The Soxhlet extraction was performed to confirm the crosslinked structure of the polymers. The high yield of the insoluble fraction showed that all monomers participated in the formation of the crosslinked structure. The results are summarized in Table 3. The lower

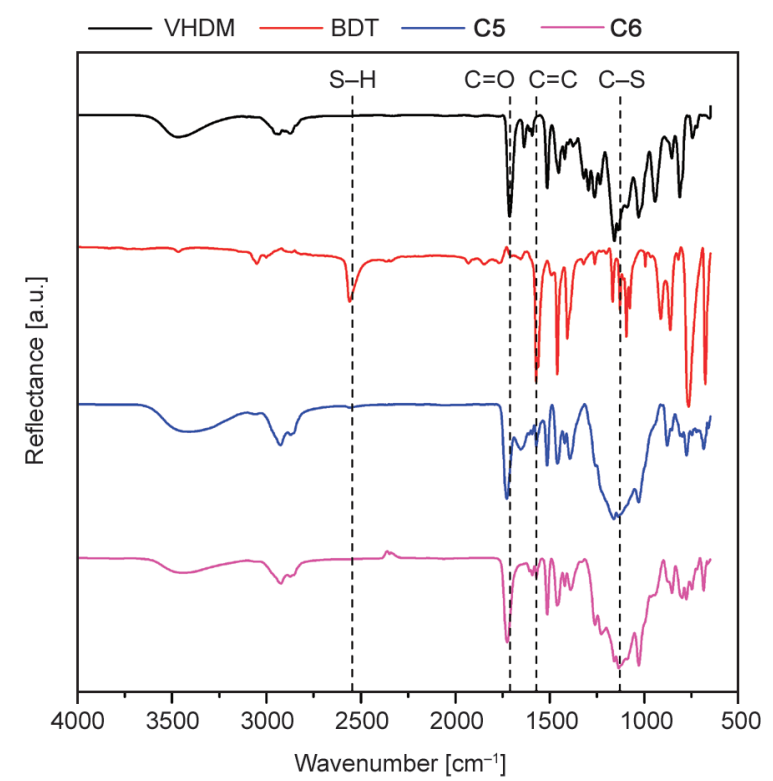

Figure 4. FT-IR spectra of VHDM, BDT and the crosslinked polymers $\mathbf{C 5}$ and $\mathbf{C 6}$. values of the insoluble fraction (82-87\%) were obtained when $1 \mathrm{~mol}$ of BDT was used compared to polymers with $0.5 \mathrm{~mol}$ of BDT (95-100\%). Higher values of the insoluble fraction correlate with the swelling values of the resulting polymers (Figure 5). Lower values of the polymer swelling indicate that shorter chains were formed between the crosslinking points in the polymers. A small signal of unreacted thiol groups was observed in FT-IR spectra of polymers prepared with $1 \mathrm{~mol}$ of thiol $(\mathbf{C 1}, \mathbf{C 3}$, and $\mathbf{C 5})$. The presence of unreacted functional groups shows that fewer crosslinks were formed in the polymers, and thus the high swelling value of polymer samples and the reduced yield of insoluble fraction were obtained [42]. During extraction in acetone, soluble components (unreacted monomers, linear oligomers, or branched oligomers) were washed out, resulting in lower values of the gel fraction. The swelling values of polymers with $0.5 \mathrm{~mol}$ of thiol were much lower (4-9\%) than those of polymers prepared with $1 \mathrm{~mol}$ of thiol (35-22\%) as the result of the denser interpenetrating networks formed.

The highest swelling value in acetone of all vanillin acrylate-based polymers synthesized with 1 mol of thiol was determined for the VHDM-based polymer C5. This is the result of a more flexible polymer network due to the longer chains between the crosslinking points [43]. VD- and VDM-based polymers with

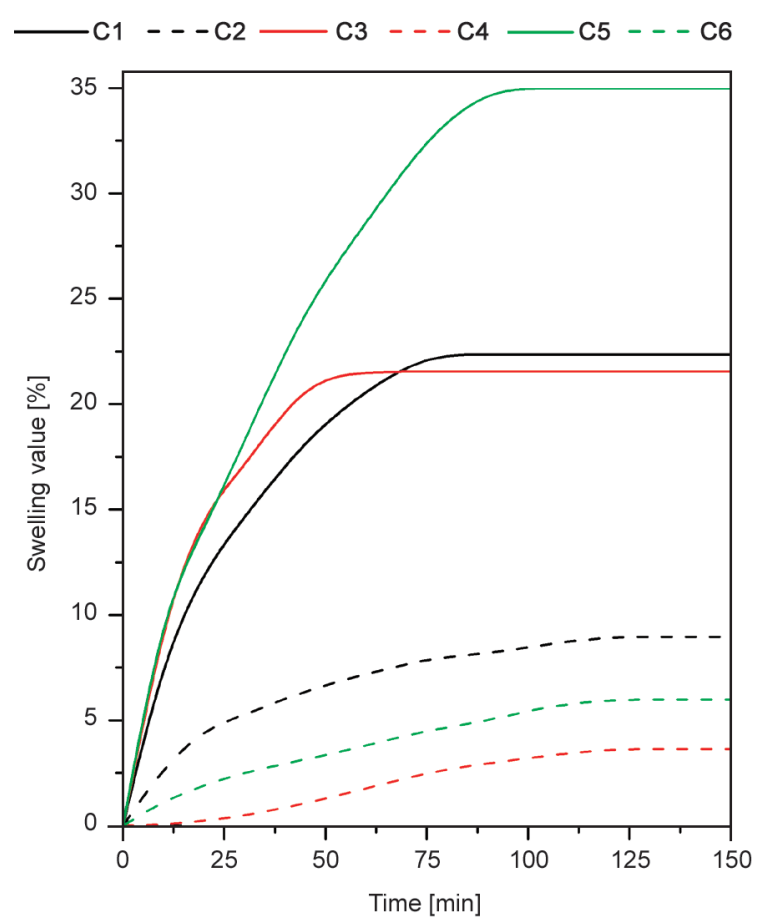

Figure 5. The swelling values of vanillin-basedpolymers in acetone. 
Table 3. Characteristics of the crosslinked vanillin-based polymers.

\begin{tabular}{|c|c|c|}
\hline Polymer & $\begin{array}{c}\text { Yield of insoluble fraction } \\
{[\%]}\end{array}$ & $\begin{array}{c}\text { Swelling value in acetone } \\
{[\mathbf{\%}]}\end{array}$ \\
\hline C1 & $85 \pm 0.5$ & $22 \pm 2.0$ \\
\hline C2 & $99.6 \pm 0.5$ & $9 \pm 1.0$ \\
\hline C3 & $82 \pm 0.5$ & $22 \pm 2.0$ \\
\hline C4 & $95 \pm 1.0$ & $4 \pm 0.5$ \\
\hline C5 & $87 \pm 0.5$ & $35 \pm 2.5$ \\
\hline C6 & $99.9 \pm 0.0$ & $6 \pm 0.5$ \\
\hline
\end{tabular}

$1 \mathrm{~mol}$ of BDT resulted in similar swelling values in acetone. This might be due to the similar polymer structure as similar length chains between the crosslinking points, which influence the swelling value of polymers, were formed in the polymers [44].

For polymers synthesized with $0.5 \mathrm{~mol}$ of thiol, the swelling value in acetone was quite similar (9-4\%). The swelling value for VD-based polymer $\mathbf{C 2}$ was the highest due to the longer chains between the crosslinking points in the polymer structure in comparison with VDM- and VHDM-based polymers synthesized with $0.5 \mathrm{~mol}$ of thiol [43]. The swelling test confirmed that longer chains between the crosslinking points were formed in the polymer during photopolymerization of VD with $0.5 \mathrm{~mol}$ of BDT. The shortest chains between the crosslinking points were formed in the VDM-based polymer $\mathbf{C 4}$, as its swelling value in acetone was the lowest. However, the differences in swelling values in acetone between different vanillin acrylate-based polymers are relatively insignificant and deviate in less than $10 \%$.

\subsection{Thermal properties}

DSC and TGA were used to study the thermal properties of the vanillin acrylate-based photo-crosslinked polymers. The results are summarized in Table 4 . The synthesized polymers are amorphous materials and underwent the glass transition $\left(T_{\mathrm{g}}\right)$ only, as seen from the DSC curves (Figure 6). The $T_{\mathrm{g}}$ of the polymers synthesized with $1 \mathrm{~mol}$ of BDT $\left(-3-17^{\circ} \mathrm{C}\right)$ was significantly lower than that of the polymers synthesized with $0.5 \mathrm{~mol}$ of BDT (40$46^{\circ} \mathrm{C}$ ). It was due to the unreacted BDT and the formation of the less dense inner structure, which decreased their $T_{\mathrm{g}}$ [45]. The lowest $T_{\mathrm{g}}\left(-3^{\circ} \mathrm{C}\right)$ was recorded for VDM-based polymer $\mathbf{C} \mathbf{3}$ synthesized with $1 \mathrm{~mol}$ of thiol and solvent. The low value of $T_{\mathrm{g}}$ was the result of the formation of a large amount of the thioether linkages, the low crosslinking density, and the yield of the insoluble fraction [46]. The $T_{\mathrm{g}}$

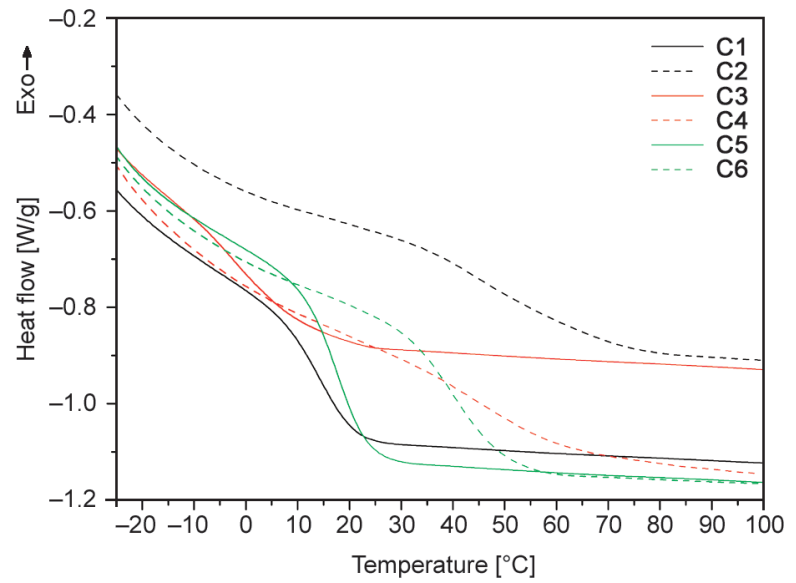

Figure 6. DSC thermograms of cross-linked polymers. - VD-based resins, - VDM-based resins, — VHDM-based resins, solid line - presence of $1 \mathrm{~mol}$ of BDT, split line - presence of $0.5 \mathrm{~mol}$ of BDT.

of VD- and VHDM-based polymers synthesized with 1 mol of thiol was similar; only the VDM-based polymer synthesized with $1 \mathrm{~mol}$ of thiol had a lower $T_{\mathrm{g}}$. These results correlated with the results of the swelling test. The highest $T_{\mathrm{g}}$ was shown by VD- and VDM-based polymers synthesized with 0.5 BDT and THF (only for VDM-based polymer); the $T_{\mathrm{g}}$ of both polymers, $\mathbf{C} 2$ and $\mathbf{C 4}$, was $46^{\circ} \mathrm{C}$. Rigidity is one of the factors that affect the $T_{\mathrm{g}}$ of polymers [47]. The same value of a $T_{\mathrm{g}}$ is the result of similar rigidity of the polymers obtained from the photorheological study. Slightly lower $T_{\mathrm{g}}\left(40^{\circ} \mathrm{C}\right)$ was observed for VHDM-based polymer synthesized with 0.5 thiols, C6. The rigidity of this VHDM-based polymer was higher than that of the VD- and VDM-based ones, and this led to the higher $T_{\mathrm{g}}$ value of this polymer. A slightly lower glass transition temperature was obtained due to the flexible backbone structure of the VHDM-based polymer, as the $T_{\mathrm{g}}$ of flexible materials is lower than that of hard and rigid polymers [48].

Table 4. Thermal characteristics of vanillin-based polymers.

\begin{tabular}{|c|c|c|c|}
\hline Polymer & $\begin{array}{c}\boldsymbol{T}_{\text {dec.-10\% }}{ }^{*} \\
{\left[{ }^{\circ} \mathbf{C}\right]^{*}}\end{array}$ & $\begin{array}{c}\boldsymbol{T}_{\mathbf{g}}^{* *} \\
{\left[{ }^{\circ} \mathbf{C}\right]}\end{array}$ & $\begin{array}{c}\mathbf{1 0} \boldsymbol{\mu m} \text { deformation } \\
\text { temperature }^{* * *} \\
{\left[{ }^{\circ} \mathbf{C}\right]}\end{array}$ \\
\hline $\mathbf{C 1}$ & 317 & 14 & 9 \\
\hline $\mathbf{C} 2$ & 324 & 46 & 16 \\
\hline $\mathbf{C 3}$ & 277 & -3 & -12 \\
\hline $\mathbf{C 4}$ & 294 & 46 & 5 \\
\hline $\mathbf{C 5}$ & 327 & 17 & 8 \\
\hline $\mathbf{C 6}$ & 341 & 40 & 14 \\
\hline
\end{tabular}

*from TGA curves,

${ }^{* *}$ from DSC curves,

${ }^{* * *}$ from compression under load curves. 
Thermal decomposition of the synthesized polymers occurred in two steps for VDM-based polymers with THF and in one step for VD and VHDM-based polymers without any solvent. (Figure 7). The first step can be explained by the formation of linear or branched macromolecules in the presence of the solvent, which acts as a chain transfer agent [49]. The first step in the TGA curve of polymer $\mathbf{C} \mathbf{3}$ can also be explained by the evaporation or cleavage of the fragments with unreacted BDT, as unreacted thiol group signals were observed in the FT-IR spectrum of polymer $\mathbf{C} 3$ [42]. The temperature of $10 \%$ weight loss $\left(T_{\text {dec.-10\% }}\right)$ of all synthesized polymers was in the range of $277-341^{\circ} \mathrm{C}$. Similarly to the glass transition temperature, the values of $T_{\text {dec.-10\% }}$ for polymers synthesized from the resins with $0.5 \mathrm{~mol}$ of BDT were higher. These results correlated with the yield of the insoluble fraction of polymers as higher decomposition temperatures were obtained for polymers with a higher yield of insoluble fraction and denser internal network structure. The value of $T_{\text {dec.-10\% }}$ for VHDM-based polymer synthesized with $0.5 \mathrm{~mol}$ of thiol C6 $\left(T_{\text {dec. }-10 \%}=341{ }^{\circ} \mathrm{C}\right)$ was the highest and the lowest $T_{\text {dec.-10\% }}$ was recorded for VDM-based polymer synthesized with $1 \mathrm{~mol}$ of thiol and solvent $\mathbf{C 3}$ $\left(T_{\text {dec. }-10 \%}=277^{\circ} \mathrm{C}\right) \cdot T_{\text {dec. }-10 \%}$ of the synthesized polymers were in a similar range as for some acrylated epoxidized soybean oil-based polymers $\left(297-356^{\circ} \mathrm{C}\right)$ tested in optical 3D printing [50]. This similarity indicates that vanillin-based polymers obtained in this study can be potentially used in optical 3D printing. Their thermal characteristics are comparable with

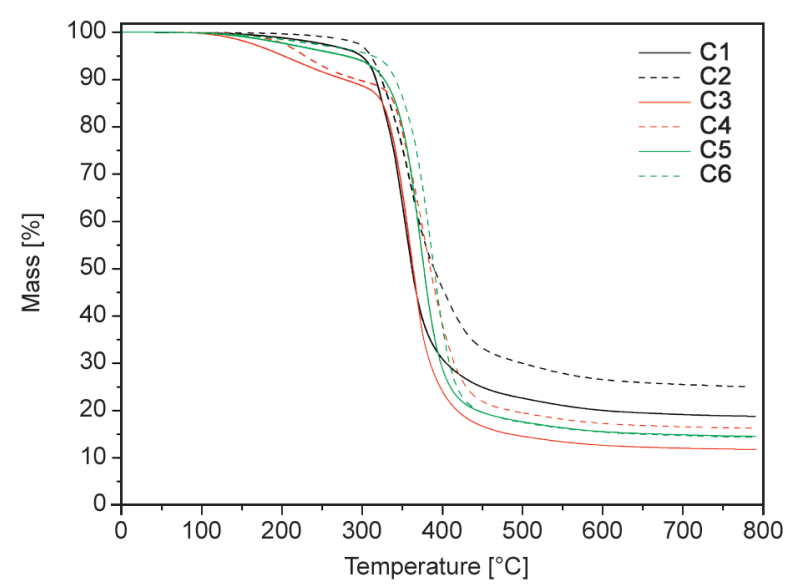

Figure 7. Thermogravimetric curves of cross-linked polymers. - VD-based resins, - VDM-based resins, — VHDM-based resins, solid line - presence of $1 \mathrm{~mol}$ of BDT, split line - presence of $0.5 \mathrm{~mol}$ of BDT. those of soybean oil-based polymers used in optical $3 \mathrm{D}$ printing technology.

The curves of the specimen deformation under load are presented in Figure 7. The $10 \mu \mathrm{m}$ deformation temperature was chosen for comparison because, at this value of deformation, all six polymers can be compared. It would be impossible to compare them using different deformation values because deformation values of polymers prepared with $0.5 \mathrm{~mol}$ of thiol are very low, while the ones for polymers prepared with $1 \mathrm{~mol}$ of thiol are higher. The values of the temperature at which the $10 \mu \mathrm{m}$ deformation of the sample is reached are summarized in Table 4. The $10 \mu \mathrm{m}$ deformation temperature is the temperature at which polymers deform under a load of $5 \mathrm{~N}$. Even at a temperature lower than $T_{\mathrm{g}}$; these polymers can slightly deform. This deformation increases as the temperature increases. The highest temperature of the deformation beginning was exhibited by the C6 specimen (Figure 8). In all cases, the deformation of the polymers prepared with $1 \mathrm{~mol}$ of thiol started at a lower temperature than that of the polymers synthesized with $0.5 \mathrm{~mol}$ of thiol. Furthermore, the $10 \mu \mathrm{m}$ deformation temperature of polymers synthesized with $1 \mathrm{~mol}$ thiol was lower than that of the same vanillin acrylate-based polymers synthesized with $0.5 \mathrm{~mol}$ of thiol. For example, the $10 \mu \mathrm{m}$ deformation temperature of vanillin diacrylate-based polymer synthesized with $1 \mathrm{~mol}$ of thiol $\mathbf{C 1}$ was $9{ }^{\circ} \mathrm{C}$, while that of vanillin diacrylate-based polymer synthesized with $0.5 \mathrm{~mol}$ of thiol $\mathbf{C} 2$ was $16^{\circ} \mathrm{C}$. All of these results correlated with the $T_{\mathrm{g}}$ determined by DSC.

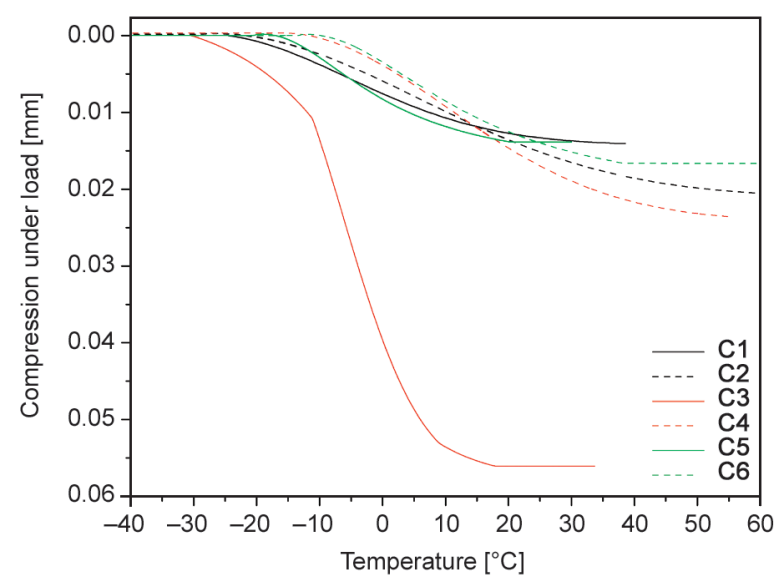

Figure 8. Compression under load as a function of temperature of cross-linked polymers. - VD-based resins, — VDM-based resins, - VHDM-based resins, solid line - presence of 1 mol of BDT, split line presence of $0.5 \mathrm{~mol}$ of BDT. 
The lowest $10 \mu \mathrm{m}$ deformation temperature was obtained for VDM-based polymers $\mathbf{C} \mathbf{3}$ and $\mathbf{C 4}$. It can be explained by the formation of a large number of the thioether linkages, the low cross-linking density, and the yield of the insoluble fraction. The VD- and VHDM-based polymers synthesized with 1 and 0.5 mol of thiol showed very similar $10 \mu \mathrm{m}$ deformation temperatures, although those of the VHDMbased polymers were slightly lower, which can be explained by the flexible backbone structure of the VHDM-based polymer.

\subsection{Shape memory properties of vanillin-based polymers}

The shape memory of polymers significantly expands their field of application. In order to test shape memory properties of vanillin-based polymers, the polymer samples were heated above their glass transition temperature and then deformed to the desired temporary shape, in this case - a coil. The glass stick was used to form polymer samples. When the temporary shape was obtained, it was fixed by cooling the polymer sample below its $T_{\mathrm{g}}$. The temporary shape did not change with time, while samples were kept at a temperature below their $T_{\mathrm{g}}$. The ability of the samples to return to their permanent shape was verified by heating them above their $T_{\mathrm{g}}$. All polymer samples returned to their permanent shape within a short period of time. The recovery to the original shape conditions of these polymers is determined by their glass transition temperature [1]. The scheme of the heating-cooling-heating cycles is presented in Figure 9.

The ability to obtain a new shape while heated above $T_{\mathrm{g}}$ and maintain it after cooling of the polymer specimen below $T_{\mathrm{g}}$ was demonstrated by all synthesized vanillin-based polymers. All of them were able to return to their primary shape after heating above $T_{\mathrm{g}}$. The polymers, prepared with $1 \mathrm{~mol}$ of thiol, were transformed to a temporary shape at room temperature $\left(25^{\circ} \mathrm{C}\right)$ and then placed in the fridge $\left(-20^{\circ} \mathrm{C}\right)$ to maintain their temporary shape. These polymers were able to maintain their temporary shape in the fridge but did not maintain it at room temperature, as their $T_{\mathrm{g}}$ is below $25^{\circ} \mathrm{C}$, and that limits their application. The VDM-based polymer $\mathbf{C} \mathbf{3}$ sample returned to its permanent shape at room temperature, the fastest of all polymers synthesized with $1 \mathrm{~mol}$ of thiol, within less than 90 seconds. VD and VHDM-based polymer $\mathbf{C} 1$ and $\mathbf{C 5}$ samples returned to their permanent shape slower; it took about $180 \mathrm{~s}$ to fully recover at room temperature. The transformation of the $\mathbf{C 1}$ sample is presented in Figure 9b.

Polymers, prepared with $0.5 \mathrm{~mol}$ of thiol, were transformed to a temporary shape at $60^{\circ} \mathrm{C}$ and then cooled to room temperature $\left(25^{\circ} \mathrm{C}\right)$. The samples of a)

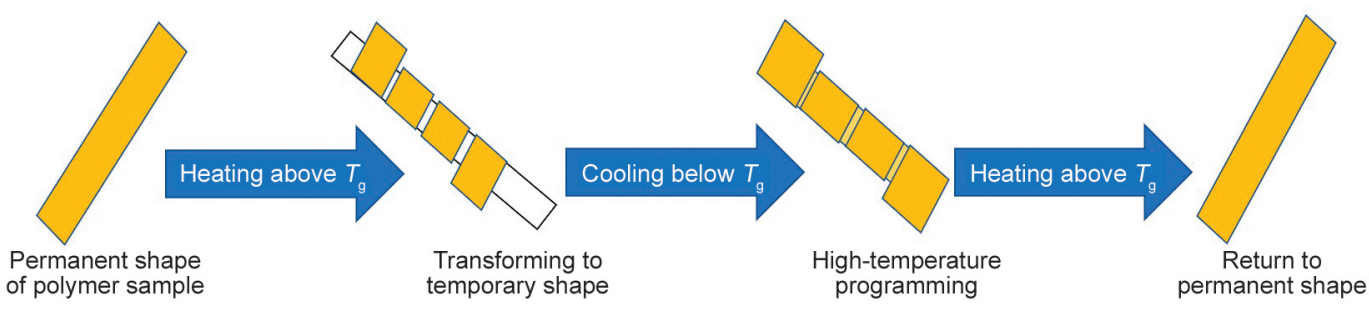

b)

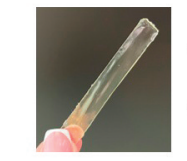

Permanent shape of polymer sample
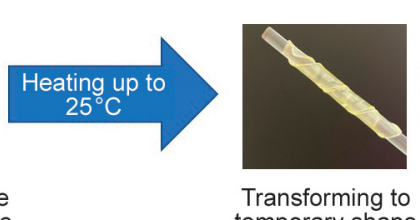
temporary shape

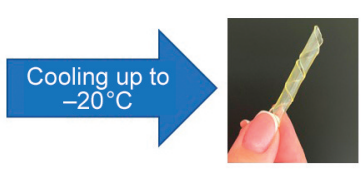

High-temperatur programming

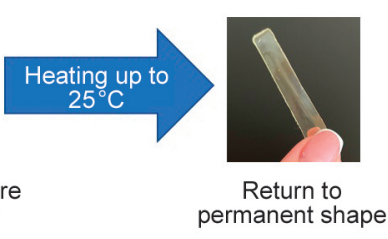

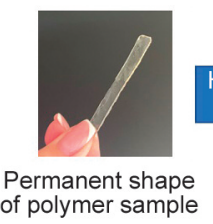

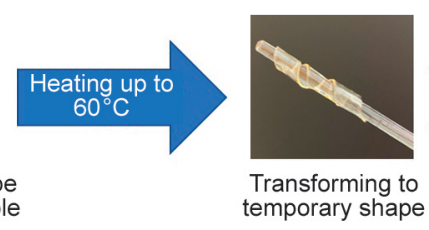

c)
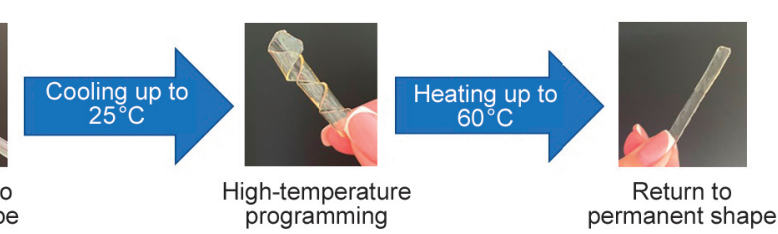

Figure 9. The scheme of shape memory behaviour of polymer samples, a) principal scheme of experiment, b) sample of VD-based polymer synthesized with $1 \mathrm{~mol}$ of thiol, C1, c) sample of VHDM-based polymer synthesized with $0.5 \mathrm{~mol}$ of thiol, C6. 
these polymers were able to maintain their temporary shape at room temperature. No change in shape was noticed after 48 hours at $25^{\circ} \mathrm{C}$. To return to a permanent shape, polymer samples were heated to $60^{\circ} \mathrm{C}$. At this temperature, all samples immediately returned to their permanent shape in less than a second. Samples of acrylate-based polymers demonstrated the same results, as their $T_{\mathrm{g}} \mathrm{s}$ are very similar, and no differences were observed between VD-, VDM- and VHDM-based polymers synthesized with $0.5 \mathrm{~mol}$ of thiol. The transformation of $\mathbf{C 6}$ is presented in Figure 9c.

\subsection{Mechanical characteristics}

The tensile test was performed to investigate the mechanical properties of vanillin-based polymers. The results are presented in Table 5 and Figure 10. Polymers synthesized with 1 mol of vanillin derivative and $1 \mathrm{~mol}$ of thiol are soft and flexible materials; all of them demonstrated low values of Young's modulus (1.4-3.5 MPa) and tensile strength (0.02-4.1 MPa) compared to polymers prepared with $0.5 \mathrm{~mol}$ of thiol. Significantly high values of elongation at break were shown by VD- and VHDM-based polymers synthesized with $1 \mathrm{~mol}$ of thiol, C1 (102.8\%), and C5 (119.7\%). The high elongation at break values and shape memory abilities of these polymers allow using them as thermo-responsive smart materials in various areas such as aerospace, medicine, civil engineering and etc. [51]. The lower values of Young's modulus and tensile strength of polymers synthesized with 1 mol of thiol compared to those of polymers synthesized with $0.5 \mathrm{~mol}$ of thiol are due to the polymer structure. The crosslinking density of the polymers synthesized with $0.5 \mathrm{~mol}$ of thiol is higher as the short chains between the crosslinking points were formed. Polymers synthesized with $1 \mathrm{~mol}$ of thiol demonstrated lower values of mechanical characteristics as they have longer chains between

Table 5. Mechanical characteristics of the polymers obtained by tensile test.

\begin{tabular}{|c|c|c|c|}
\hline Polymer & $\begin{array}{c}\text { Young's } \\
\text { modulus } \\
{[\mathbf{M P a}]}\end{array}$ & $\begin{array}{c}\text { Tensile } \\
\text { strength } \\
{[\mathbf{M P a}]}\end{array}$ & $\begin{array}{c}\text { Elongation at } \\
\text { break } \\
{[\mathbf{\%}]}\end{array}$ \\
\hline $\mathbf{C} \mathbf{1}$ & $3.5 \pm 0.2$ & $4.1 \pm 0.7$ & $102.8 \pm 3.6$ \\
\hline $\mathbf{C 2}$ & $9610.8 \pm 372.4$ & $349.9 \pm 19.0$ & $6.8 \pm 1.1$ \\
\hline $\mathbf{C 3}$ & $1.4 \pm 0.2$ & $0.02 \pm 0.0$ & $19.0 \pm 3.2$ \\
\hline $\mathbf{C 4}$ & $3952.3 \pm 52.3$ & $177.9 \pm 11.6$ & $9.7 \pm 0.3$ \\
\hline C5 & $1.4 \pm 0.1$ & $1.2 \pm 0.1$ & $119.7 \pm 12.1$ \\
\hline C6 & $11339.4 \pm 934.0$ & $439.0 \pm 8.2$ & $12.3 \pm 1.2$ \\
\hline
\end{tabular}

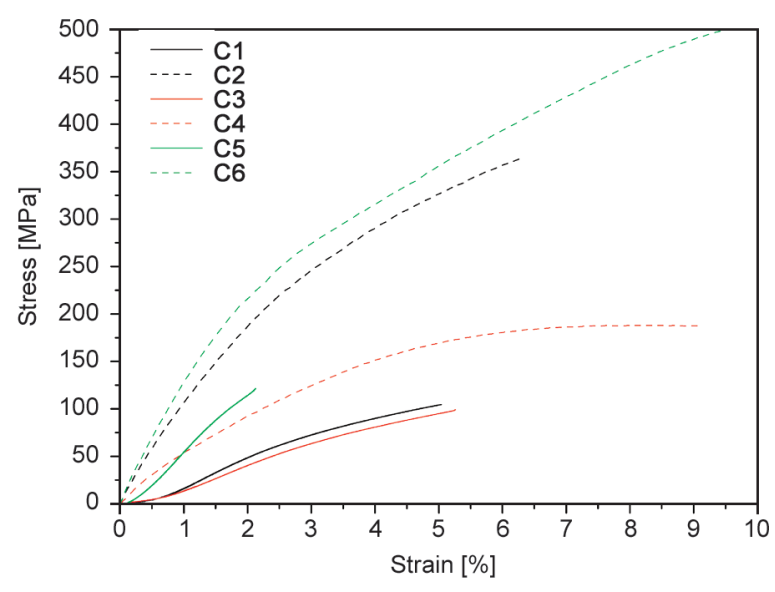

Figure 10. Tensile stress-strain curves of cross-linked polymers. - VD-based resins, - VDM-based resins, - VHDM-based resins, solid line - presence of $1 \mathrm{~mol}$ of BDT, split line - presence of $0.5 \mathrm{~mol}$ of BDT.

the crosslinking points. These results were confirmed by the swelling test. Vanillin-based polymers synthesized with $1 \mathrm{~mol}$ of thiol have longer chains between the crosslinking points, which resulted in lower mechanical strength and higher elongation at break values [52]. Different results were shown by vanillin-based polymers synthesized with $0.5 \mathrm{~mol}$ of thiol. The high values of Young's modulus, tensile strength, and low values of elongation at break show that these polymers are mechanically strong and rigid materials. Polymers synthesized from vanillin derivatives and $0.5 \mathrm{~mol}$ of thiol demonstrated similarly and, in most cases, even higher mechanical strength compared to acrylated epoxidized soybean oil-based polymers used in digital light processing 3D printing [53].

As confirmed by elongation at break values, VHDMbased polymers synthesized with 0.5 and $1 \mathrm{~mol}$ of thiol have a more flexible structure than VD- and VDM-based polymers. Flexible polymers can stretch more before breaking [48], and this ability is caused by their structure. The swelling test has confirmed that longer chains between the crosslinking points were formed during the photopolymerization of VHDM, resulting in higher values of elongation at break. VDM-based polymers demonstrated the lowest values of Young's modulus, tensile strength, and elongation at break compared to VD- and VHDMbased polymers. The lower values of the mechanical characteristics were caused by linear or branched macromolecules formed in the presence of a solvent, which could act as a chain transfer agent [49]. 


\subsection{Antimicrobial activity of polymers}

The antibacterial and antifungal activity of the vanillin acrylate-based polymer films was evaluated during the direct contact with the specimens by calculating the log reduction and percent reduction of viable microbial spores. Two reference polymer films of chitosan, a well-known antibacterial polymer, and hydroxyethyl starch possessing no such activity were used as a control. The (W) in the polymer code indicates that the polymer film was washed before antimicrobial testing in acetone for $24 \mathrm{~h}$. The results are presented in Table 6 and Table 7.

The antibacterial activity of the polymer films differed in the initial stage (after 2 and $6 \mathrm{~h}$ ) (Figure 11). After $2 \mathrm{~h}$ of exposure, the $\mathbf{C 2}$ film inhibited the viability of E. coli the most (91.8\%), and $S$. aureus was inhibited the most by the $\mathbf{C} 1$ film (82.0\%). Additionally, Gram-negative $E$. coli was inhibited more than
S. aureus. After 6 hours of exposure, E. coli was already inhibited by more than $90 \%$ on 6 films (C2, C3, C3(W), C4, C4(W) and C6), and growth of S. aureus was inhibited on 4 films $(\mathbf{C 1}, \mathbf{C 3}, \mathbf{C 3}(\mathbf{W})$ and C5). However, after 24 hours of exposure, bacterial viability was completely inhibited on all films tested, except the one of $S$ aureus on C2. The structure of polymers is important for their antimicrobial activity. One of the functional groups responsible for antimicrobial properties is the aromatic ring. Compounds with different amounts of this functional group were tested against Bacillus subtilis and S. aureus as Gram-positive bacteria and Salmonella typhimurium and Proteus Vulgaris as Gram-negative bacteria and showed antibacterial effect [54]. All vanillin-based photopolymers have aromatic rings in their structure and show high antibacterial activity against $S$. aureus. Hydroxyl [55], sulfur [56], and

Table 6. Characteristics of antibacterial activity of polymer film samples.

\begin{tabular}{|l|c|c|c|c|}
\hline \multirow{3}{*}{ Polymer film } & \multicolumn{2}{|c|}{ Escherichia coli } & \multicolumn{2}{c|}{ Staphylococcus aureus } \\
\cline { 2 - 5 } & Lg reduction after 24 h & $\begin{array}{c}\text { Percent reduction after 24 h } \\
\text { [\%] }\end{array}$ & Lg reduction after 24 h & $\begin{array}{c}\text { Percent reduction after 24 h } \\
\text { [\%] }\end{array}$ \\
\hline C1 & $6.88 \pm 0.00$ & $100 \pm 0.00$ & $6.67 \pm 0.00$ & $100 \pm 0.00$ \\
\hline C2 & $6.88 \pm 0.00$ & $100 \pm 0.00$ & $2.67 \pm 0.02$ & $99.8 \pm 0.02$ \\
\hline C3 & $6.88 \pm 0.00$ & $100 \pm 0.00$ & $6.67 \pm 0.00$ & $100 \pm 0.00$ \\
\hline C3(W) & $6.88 \pm 0.00$ & $100 \pm 0.00$ & $6.67 \pm 0.00$ & $100 \pm 0.00$ \\
\hline C4 & $6.88 \pm 0.00$ & $100 \pm 0.00$ & $6.67 \pm 0.00$ & $100 \pm 0.00$ \\
\hline C4(W) & $6.88 \pm 0.00$ & $100 \pm 0.00$ & $6.67 \pm 0.00$ & $100 \pm 0.00$ \\
\hline C5 & $6.88 \pm 0.00$ & $100 \pm 0.00$ & $6.67 \pm 0.00$ & $100 \pm 0.00$ \\
\hline C6 & $6.88 \pm 0.00$ & $100 \pm 0.00$ & $6.67 \pm 0.00$ & $100 \pm 0.00$ \\
\hline Chitosan & $6.88 \pm 0.00$ & $100 \pm 0.00$ & $6.67 \pm 0.00$ & $100 \pm 0.00$ \\
\hline Hydroxyethyl starch & $3.58 \pm 0.02$ & $99.9 \pm 0.02$ & $1.08 \pm 0.02$ & $91.6 \pm 0.02$ \\
\hline
\end{tabular}

${ }^{*} \mathrm{~W}$ - washed for $24 \mathrm{~h}$ in acetone

Table 7. Characteristics of antifungal activity characteristics of polymer film samples.

\begin{tabular}{|l|c|c|c|c|}
\hline \multirow{3}{*}{ Polymer film } & \multicolumn{2}{|c|}{ Aspergillus flavus } & \multicolumn{2}{c|}{ Aspergillus niger } \\
\cline { 2 - 5 } & Lg reduction after 24 h & $\begin{array}{c}\text { Percent reduction after 24 h } \\
{[\%]}\end{array}$ & Lg reduction after 24 h & $\begin{array}{c}\text { Percent reduction after 24 h } \\
\text { [\%] }\end{array}$ \\
\hline C1 & $6.22 \pm 0.00$ & $100 \pm 0.00$ & $0.80 \pm 0.09$ & $84.4 \pm 0.09$ \\
\hline C2 & $1.20 \pm 0.04$ & $93.7 \pm 0.04$ & $0.76 \pm 0.10$ & $82.9 \pm 0.10$ \\
\hline C3 & $1.49 \pm 0.05$ & $96.7 \pm 0.05$ & $0.65 \pm 0.12$ & $77.9 \pm 0.12$ \\
\hline C3(W) & $1.45 \pm 0.05$ & $96.4 \pm 0.05$ & $0.55 \pm 0.12$ & $72.3 \pm 0.12$ \\
\hline C4 & $1.16 \pm 0.04$ & $93.1 \pm 0.04$ & $0.86 \pm 0.09$ & $86.3 \pm 0.09$ \\
\hline C4(W) & $1.25 \pm 0.04$ & $94.3 \pm 0.04$ & $1.02 \pm 0.06$ & $90.6 \pm 0.06$ \\
\hline C5 & $3.22 \pm 0.01$ & $99.9 \pm 0.01$ & $1.12 \pm 0.05$ & $92.5 \pm 0.05$ \\
\hline C6 & $1.22 \pm 0.04$ & $94.0 \pm 0.04$ & $0.66 \pm 0.12$ & $78.5 \pm 0.12$ \\
\hline Chitosan & $1.76 \pm 0.06$ & $97.9 \pm 0.06$ & $2.93 \pm 0.01$ & $99.9 \pm 0.01$ \\
\hline Hydroxyethyl starch & $1.53 \pm 0.05$ & $97.0 \pm 0.05$ & $0.43 \pm 0.14$ & $63.5 \pm 0.14$ \\
\hline
\end{tabular}

${ }^{*} \mathrm{~W}$ - washed for $24 \mathrm{~h}$ in acetone 

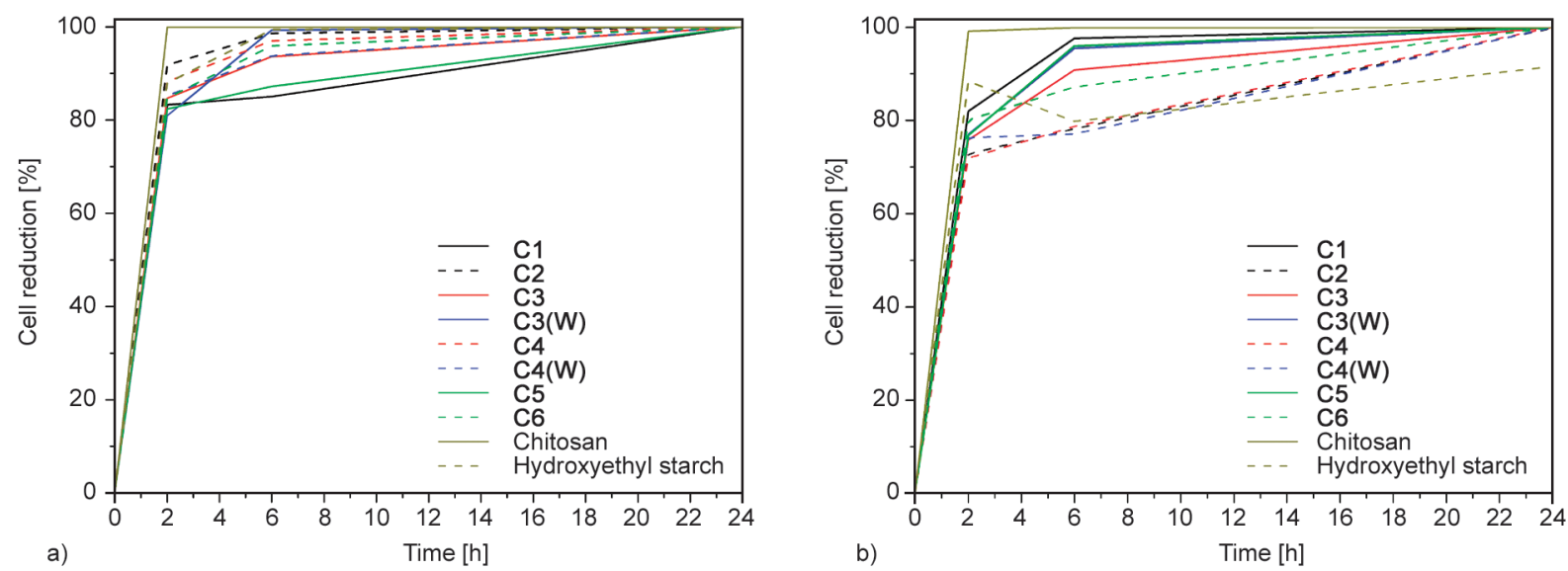

Figure 11. The reduction of E. coli (a) and $S$. aureus b) cells during $24 \mathrm{~h}$ of contact time with specimens of vanillin-based polymers, chitosan, and hydroxyethyl starch.

carbonyl [57] groups also contribute to the antimicrobial effect. It has been scientifically shown that decreasing the value of these groups leads to a lower antibacterial effect. The presence of these groups also increases the antibacterial properties of vanillinbased photopolymers. As seen from the comparison of these results with the ones for chitosan films, some of the bacteria may remain viable on the tested films for some time, but the final result is the same after $24 \mathrm{~h}$. The viability of the bacteria tested on the hydroxyethyl starch film also decreased, but they still remained viable after $24 \mathrm{~h}$.

The antifungal activity of the films varied depending on the type of fungus (Table 6). Higher antifungal activity was observed for $A$. flavus than for $A$. niger, and it gradually intensified with increasing exposure time. The viability of $A$. flavus was also inhibited on the reference samples; however, the percent reduction was higher on the $\mathbf{C 1}$ and $\mathbf{C 5}$ films than on the chitosan and hydroxyethyl starch films (100 and 99.9\%,

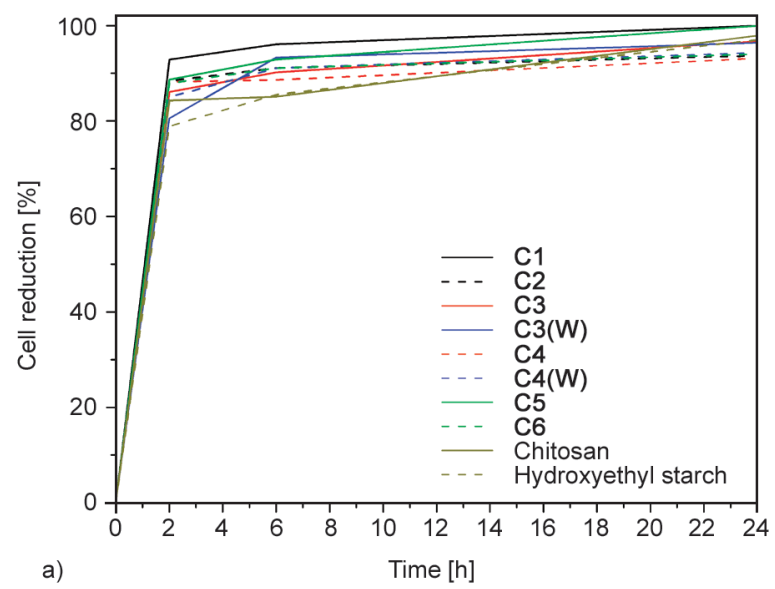

respectively). Other polymer films showed a similar percentage reduction in the range of $93.1-94.3 \%$. After inoculation of the test films with the suspension of $A$. niger spore, the percent reduction was slightly reduced after $6 \mathrm{~h}$ of exposure compared to $2 \mathrm{~h}$ of exposure, which could be explained by the onset of sporulation (Figure 12). However, after $24 \mathrm{~h}$, the viability of $A$. niger decreased due to unfavorable development conditions for the fungus and, therefore, the percent reduction increased. The results showed that the viability of $A$. niger on the hydroxyethyl starch film also decreased. The highest percent reduction was found on $\mathbf{C 4}(\mathbf{W})$ film, but it was lower than the one on chitosan film. The lower values of percent reduction against $A$. flavus and $A$. niger after $24 \mathrm{~h}$ were demonstrated by VD-, VDM- and VHDMbased films prepared with $0.5 \mathrm{~mol}$ of thiol compared to VD, VDM, and VHDM-based films prepared with $1 \mathrm{~mol}$ of thiol. The main reason for this difference could be the higher concentration of sulfur resulting

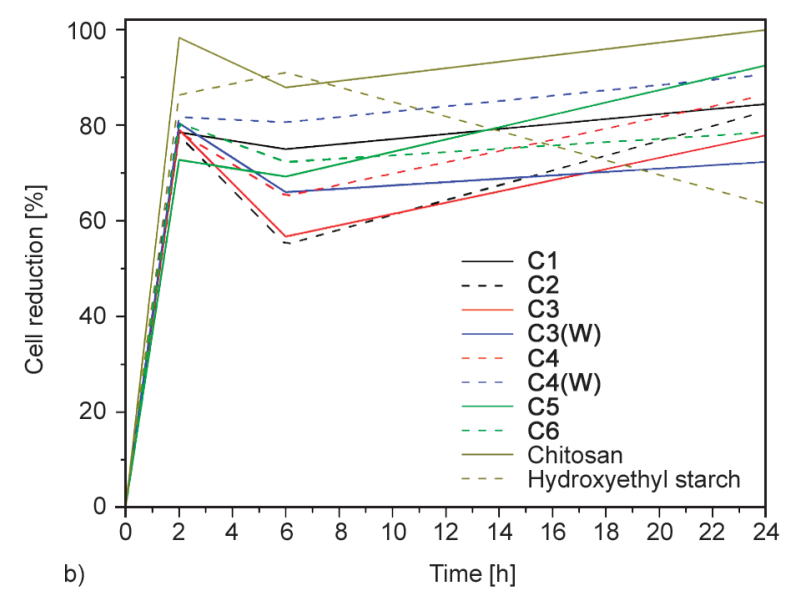

Figure 12. The reduction of A. flavus (a) and A. niger (b) cells during $24 \mathrm{~h}$ of contact time with specimens of vanillin-based polymers, chitosan, and hydroxyethyl starch. 
from the higher amount of thiol, which has marked antifungal activity [56]. The only exception was the VDM-based film, in which the percent reduction against $A$. niger was lower when $1 \mathrm{~mol}$ of thiol was used for the synthesis of the polymer in comparison to that of the polymer synthesized with $0.5 \mathrm{~mol}$ of thiol. In this case, A. niger was affected by a higher concentration of carbonyl groups in the VDM-based film prepared with $0.5 \mathrm{~mol}$ of thiol [57].

The lowest value of cell reduction against $A$. niger after $24 \mathrm{~h}$ was shown by $\mathbf{C} \mathbf{3}$ and $\mathbf{C 3}(\mathbf{W})$ films. Polymer $\mathbf{C} 3$ showed a $77.9 \%$ of percentage reduction, while the same polymer $\mathbf{C} 3(\mathbf{W})$ reached only $72.3 \%$ after $24 \mathrm{~h}$ washing procedure in acetone. It can be assumed that lower values of cell reduction were obtained due to a lower amount of carbonyl groups and sulfur in the washed sample, and the lower value after the washing procedure was due to the low value of the yield of the insoluble fraction of $\mathbf{C} 3$ polymer, as all unreacted parts of monomers and oligomers were washed out from the film and lowered the concentration of carbonyl groups and sulfur. Different results were shown by $\mathbf{C} \mathbf{4}$ polymer film before and after washing. Polymer $\mathbf{C} 4$ film without washing reached a reduction of $86.3 \%$. The reduction was increased to $90.6 \%$ in polymer $\mathbf{C} 4(\mathbf{W})$, which was washed before the test. Polymer $\mathbf{C} 4$ with a high yield of insoluble fraction resulted in the purer polymer after washing in acetone for $24 \mathrm{~h}$. Because of that, only a small amount of unreacted monomers was washed out, and a higher concentration of carbonyl groups was left in the polymer resulting in better antifungal activity against $A$. niger.

\section{Conclusions}

Novel antimicrobial vanillin acrylate-based shape memory photopolymers with high antibacterial and antifungal activity have been developed and investigated for the first time. A dual-curing process, combining free-radical photopolymerization and thiolacrylate photopolymerization, was applied for the synthesis of these polymers. The reduction of the thiol content increased the rate of photocuring, improved mechanical performance of the polymers (Young's modulus was increased from 1.4-3.5 to 3952.3$11339.4 \mathrm{MPa}$ ), and their heat resistance (the $10 \%$ weight loss increased from $277-327$ to $294-341^{\circ} \mathrm{C}$ ). Radical homopolymerization of acrylates resulted in a higher ratio of acrylate to thiol in the obtained polymers. The specimens of all synthesized vanillin-based polymers were able to obtain a new shape while heated above their glass transition temperature $(-3-$ $46^{\circ} \mathrm{C}$ ), maintain it after cooling below their glass transition temperature, and return to their primary shape after heating above their glass transition temperature. These properties have determined them as shape memory polymers and possible candidates for application as smart materials. All vanillin acrylatebased polymer films showed a significant antibacterial activity against Escherichia coli and Staphylococcus aureus (cell reduction reached 100\% after $24 \mathrm{~h}$ by most polymers), which was similar to that of the chitosan film. Vanillin-based polymer films also showed antifungal activity against Aspergillus flavus (cell reduction reached $93.1-100 \%$ after $24 \mathrm{~h}$ ) and Aspergillus niger (cell reduction reached 72.3$92.5 \%$ after $24 \mathrm{~h})$.

\section{Acknowledgements}

This research was funded by the Research Council of Lithuania (project No. S-MIP-20-17) and the EU ERDF through the INTERREG BSR Programme (ECOLABNET project \#R077).

\section{References}

[1] Yang K., Du J., Zhang Z., Ren T.: A facile strategy to fabricate robust triple-shape memory polymer. Materials Letters, 257, 126753 (2019). https://doi.org/10.1016/j.matlet.2019.126753

[2] Behl M., Lendlein A.: Shape-memory polymers. Materials Today, 10, 20-28 (2007). https://doi.org/10.1016/S1369-7021(07)70047-0

[3] Hager M. D., Bode S., Weber C., Schubert U. S.: Shape memory polymers: Past, present and future developments. Progress in Polymer Science, 50, 3-33 (2015). https://doi.org/10.1016/j.progpolymsci.2015.04.002

[4] Hassani F. A., Shi Q., Wen F., He T., Haroun A., Yang Y., Feng Y., Lee C.: Smart materials for smart healthcare-moving from sensors and actuators to self-sustained nanoenergy nanosystems. Smart Materials in Medicine, 1, 92-124 (2020).

https://doi.org/10.1016/j.smaim.2020.07.005

[5] Nasseri R., Deutschman C. P., Han L., Pope M. A., Tam K. C.: Cellulose nanocrystals in smart and stimuli-responsive materials: A review. Materials Today Advances, 5, 100055 (2020).

https://doi.org/10.1016/j.mtadv.2020.100055

[6] Grauzeliene S., Valaityte D., Motiekaityte G., Ostrauskaite J: Bio-based crosslinked polymers synthesized from functionalized soybean oil and squalene by thiol-ene UV curing. Materials, 14, 2675 (2021). https://doi.org/10.3390/ma14102675 
[7] Sha X-L., Yuan L., Liang G., Gu A.: Preparation of high performance bio-based benzoxazine resin through a green solvent-free strategy for shape memory application. Polymer, 202, 122673 (2020).

https://doi.org/10.1016/j.polymer.2020.122673

[8] Lu C., Liu Y., Liu X., Wang C., Wang J., Chu F.: Sustainable multiple- and multistimulus-shape-memory and self-healing elastomers with semi-interpenetrating network derived from biomass via bulk radical polymerization. ACS Sustainable Chemistry \& Engineering, 6, 6527-6535 (2018).

https://doi.org/10.1021/acssuschemeng.8b00329

[9] Khasraghi S. S., Shojaei A., Sundararaj U.: Bio-based UV curable polyurethane acrylate: Morphology and shape memory behaviors. European Polymer Journal, 118, 514-527 (2019).

https://doi.org/10.1016/j.eurpolymj.2019.06.019

[10] Chu H-Y., Fu H., Liu A., Wang P., Cao Y-L., Du A-F., Wang C-C.: Two silver-based coordination polymers constructed from organic carboxylate acids and 4, 4'bipyridine-like bidentate ligands: Synthesis, structure, and antimicrobial performances. Polyhedron, 188, 114684 (2020). https://doi.org/10.1016/j.poly.2020.114684

[11] Pandey A., Singh G., Singh S., Jha K., Prakash C.: 3D printed biodegradable functional temperature-stimuli shape memory polymer for customized scaffoldings. Journal of the Mechanical Behavior of Biomedical Materials, 108, 103781 (2020).

https://doi.org/10.1016/j.jmbbm.2020.103781

[12] Shaabani A., Sedghi R., Motasadizadeh H., Dinarvand R.: Self-healable conductive polyurethane with the body temperature-responsive shape memory for bone tissue engineering. Chemical Engineering Journal, 411, 128449 (2021). https://doi.org/10.1016/j.cej.2021.128449

[13] Bil M.: The effect of chitosan form on the shape memory properties of polyurethane based composites. Materials Letters, 284, 129007 (2020). https://doi.org/10.1016/j.matlet.2020.129007

[14] Ciriminna R., Fidalgo A., Meneguzzo F., Parrino F., Ilharco L. M., Pagliaro M.: Vanillin: The case for greener production driven by sustainability megatrend. ChemistryOpen, 8, 660-667 (2019). https://doi.org/10.1002/open.201900083

[15] Stanzione J. F., Sadler J. P., la Scala J. J., Reno K. H., Wool R. P.: Vanillin-based resin for use in composite applications. Green Chemistry, 14, 2346-2352 (2012). https://doi.org/10.1039/C2GC35672D

[16] Meylemans H. A., Harvey B. G., Reams J. T., Guenthner A. J., Cambrea L. R., Groshens T. J., Baldwin L. C., Garrison M. D., Mabry J. M.: Synthesis, characterization, and cure chemistry of renewable bis(cyanate) esters derived from 2-methoxy-4-methylphenol. Biomacromolecules, 14, 771-780 (2013).

https://doi.org/10.1021/bm3018438
[17] Salmi-Mani H., Terreros G., Barroca-Aubry N., AymesChodur C., Regeard C., Roger P.: Poly(ethylene terephthalate) films modified by UV-induced surface graft polymerization of vanillin derived monomer for antibacterial activity. European Polymer Journal, 103, 5158 (2018).

https://doi.org/10.1016/j.eurpolymj.2018.03.038

[18] Zhang C., Madbouly S. A., Kessler M. R.: Renewable polymers prepared from vanillin and its derivatives. Macromolecular Chemistry and Physics, 216, 18161822 (2015).

https://doi.org/10.1002/macp.201500194

[19] Zhang C., Yan M., Cochran E. W., Kessler M. R.: Biorenewable polymers based on acrylated epoxidized soybean oil and methacrylated vanillin. Materials Today Communications, 5, 18-22 (2015). https://doi.org/10.1016/j.mtcomm.2015.09.003

[20] Aymes-Chodur C., Salmi-Mani H., Dragoe D., AubryBarroca N., Buchotte M., Roger P.: Optimization of microwave plasma treatment conditions on polydimethylsiloxane films for further surface functionalization. European Polymer Journal, 150, 110416 (2021). https://doi.org/10.1016/j.eurpolymj.2021.110416

[21] Fache M., Boutevin B., Caillol S.: Vanillin, a key-intermediate of biobased polymers. European Polymer Journal, 68, 488-502 (2015).

https://doi.org/10.1016/j.eurpolymj.2015.03.050

[22] Roig A., Ramis X., de la Flor S., Serra À.: Dual-cured thermosets from glycydil methacrylate obtained by epoxy-amine reaction and methacrylate homopolymerization. Reactive and Functional Polymers, 159, 104822 (2021). https://doi.org/10.1016/j.reactfunctpolym.2021.104822

[23] Ye Y-S., Rick J., Hwang B-J.: Water soluble polymers as proton exchange membranes for fuel cells. Polymers, 4, 913-963 (2012). https://doi.org/10.3390/polym4020913

[24] Fouassier J. P., Lalevée J.: Photochemical production of interpenetrating polymer networks; Simultaneous initiation of radical and cationic polymerization reactions. Polymers, 6, 2588-2610 (2014). https://doi.org/10.3390/polym6102588

[25] Roland C. M.: Interpenetrating polymer networks (IPN): Structure and mechanical behavior. in 'Encyclopedia of polymeric nanomaterials' (eds.: Kobayashi, S., Müllen K.) Springer, Berlin, 1-9 (2013). https://doi.org/10.1007/978-3-642-36199-9 91-1

[26] Xi W., Peng H., Aguirre-Soto A., Kloxin C. J., Stansbury J. W., Bowman C. N.: Spatial and temporal control of thiol-Michael addition via photocaged superbase in photopatterning and two-stage polymer networks formation. Macromolecules, 47, 6159-6165 (2014). https://doi.org/10.1021/ma501366f 
[27] Konuray A. O., Ruiz A., Morancho J. M., Salla J. M., Fernández-Francos X., Serra À., Ramis X.: Sequential dual curing by selective Michael addition and free radical polymerization of acetoacetate-acrylate-methacrylate mixtures. European Polymer Journal, 98, 39-46 (2018). https://doi.org/10.1016/j.eurpolymj.2017.11.003

[28] Gamardella F., Sabatini V., Ramis X., Serra À.: Tailormade thermosets obtained by sequential dual-curing combining isocyanate-thiol and epoxy-thiol click reactions. Polymer, 174, 200-209 (2019). https://doi.org/10.1016/j.polymer.2019.04.041

[29] Green W. A.: Industrial photoiniciators. A technical guide. CRC Press, Florida (2010).

[30] Navaruckiene A., Skliutas E., Kasetaite S., Rekštytė S., Raudoniene V., Bridziuviene D., Malinauskas M., Ostrauskaite J.: Vanillin acrylate-based resins for optical 3D printing. Polymers, 12, 397 (2020). https://doi.org/10.3390/polym12020397

[31] Bagheri A., Jin J.: Photopolymerization in 3D printing. ACS Applied Polymer Materials, 1, 593-611 (2019). https://doi.org/10.1021/acsapm.8b00165

[32] Gurr M., Mülhaupt R.: Rapid prototyping. in 'Polymer science: A comprehensive reference' (eds.: Matyjaszewski K., Möller M.) Elsevier, Edinburgh, 77-99 (2012).

[33] Mezger T. G.: The rheology handbook. Vincentz Network, Hanover (2011).

[34] Konuray O., Fernández-Francos X., Ramis X., Serra À.: State of the art in dual-curing acrylate systems. Polymers, 10, 178 (2018). https://doi.org/10.3390/polym10020178

[35] Nair D. P., Podgórski M., Chatani S., Gong T., Xi W., Fenoli C. R., Bowman C. N.: The thiol-Michael addition click reaction: A powerful and widely used tool in materials chemistry. Chemistry of Materials, 26, 724744 (2014). https://doi.org/10.1021/cm402180t

[36] Candan Z., Gardner D. J., Shaler S. M.: Dynamic mechanical thermal analysis (DMTA) of cellulose nanofibril/nanoclay/pMDI nanocomposites. Composites Part B: Engineering, 90, 126-132 (2016). https://doi.org/10.1016/j.compositesb.2015.12.016

[37] Jian Y., He Y., Jiang T., Li C., Yang W., Nie J.: Volume shrinkage of UV-curable coating formulation investigated by real-time laser reflection method. Journal of Coatings Technology and Research, 10, 231-237 (2013). https://doi.org/10.1007/s11998-012-9446-2

[38] Simula A., Ballard N., Aguirre M., Leiza J. R., van Es S., Asua J. M.: Nitroxide mediated copolymerization of acrylates, methacrylates and styrene: The importance of side reactions in the polymerization of acrylates. European Polymer Journal, 110, 319-329 (2019).

https://doi.org/10.1016/j.eurpolymj.2018.11.041

[39] Shortall A. C.: How light source and product shade influence cure depth for a contemporary composite. Journal of Oral Rehabilitation, 32, 906-911 (2005). https://doi.org/10.1111/j.1365-2842.2005.01523.x
[40] Buruiana T., Melinte V., Stroea L., Buruiana E.: Urethane dimethacrylates with carboxylic groups as potential dental monomers. Synthesis and properties. Polymer Journal, 41, 978-987 (2009).

https://doi.org/10.1295/polymj.PJ2009131

[41] Meereis C. T. W., Leal F. B., Lima G. S., de Carvalho R. V., Piva E., Ogliari F. A.: BAPO as an alternative photoinitiator for the radical polymerization of dental resins. Dental Materials, 30, 945-953 (2014).

https://doi.org/10.1016/j.dental.2014.05.020

[42] Popescu I., Turtoi M., Suflet D. M., Dinu M. V., DarieNita R. N., Anghelache M., Calin M., Constantin M.: Alginate/poloxamer hydrogel obtained by thiol-acrylate photopolymerization for the alleviation of the inflammatory response of human keratinocytes. International Journal of Biological Macromolecules, 180, 418-431 (2021). https://doi.org/10.1016/j.ijbiomac.2021.03.082

[43] Saalwächter K., Chassé W., Sommer J-U.: Structure and swelling of polymer networks: Insights from NMR. Soft Matter, 29, 6587-6593 (2013).

https://doi.org/10.1039/C3SM50194A

[44] Subraman R., Izquierdo-Alvarez A., Bhattacharya P., Meerts M., Moldenaers P., Ramon H., van Oosterwyck H.: The influence of swelling on elastic properties of polyacrylamide hydrogels. Frontiers in Materials, 7, 212 (2020). https://doi.org/10.3389/fmats.2020.00212

[45] Campo E. A.: Thermal properties of polymeric materials. in 'Selection of polymeric materials' (ed.: Campo E. A.) William Andrew, New York, 103-140 (2008). https://doi.org/10.1016/B978-081551551-7.50005-X

[46] Xie R., Weisen A. R., Lee Y., Aplan M. A., Fenton A. M., Masucci A. E., Kempe F., Sommer M., Pester C. W., Colby R. H., Gomez E. D.: Glass transition temperature from the chemical structure of conjugated polymers. Nature Communications, 11, 893 (2020). https://doi.org/10.1038/s41467-020-14656-8

[47] Ebnesajjad S.: Introduction to plastics. in 'Chemical resistance of commodity thermoplastics' (eds.: Baur E., Ruhrberg K., Woishnis W.) William Andrew, New York, XIII-XXV (2016).

https://doi.org/10.1016/B978-0-323-47358-3.00017-X

[48] Shrivastava A.: Introduction to plastics engineering. in 'Introduction to plastics engineering' (ed.: Shrivastava A.) William Andrew, New York, 1-16 (2018). https://doi.org/10.1016/B978-0-323-39500-7.00001-0

[49] Valdebenito A., Encinas M. V.: Effect of solvent on the free radical polymerization of $N, N$-dimethylacrylamide. Polymer International, 59, 1246-1251 (2010). https://doi.org/10.1002/pi.2856

[50] Lebedevaite M., Ostrauskaite J., Skliutas E., Malinauskas M.: Photoinitiator free resins composed of plant-derived monomers for the optical $\mu$-3D printing of thermosets. Polymers, 11, 116 (2019). https://doi.org/10.3390/polym11010116 
[51] Mukherjee A., Deepmala, Srivastava P., Sandhu J. K.: Application of smart materials in civil engineering: A review. Materials Today, in press (2021). https://doi.org/10.1016/j.matpr.2021.03.304

[52] Aguilar-Vega M.: Structure and mechanical properties of polymers. in 'Handbook of polymer synthesis, characterization, and processing' (eds.: Saldívar-Guerra E., Vivaldo-Lima E.) Wiley, New Jersey, 425-434 (2013). https://doi.org/10.1002/9781118480793.ch21

[53] Lebedevaite M., Talacka V., Ostrauskaite J.: High biorenewable content acrylate photocurable resins for DLP 3D printing. Journal of Applied Polymer Science, 138, 50233 (2020).

https://doi.org/10.1002/app.50233

[54] Patel C., Bassin J. P., Scott M., Flye J., Hunter A. P., Martin L., Goyal M.: Synthesis and antimicrobial activity of 1,2-benzothiazine derivatives. Molecules, 21, 861 (2016).

https://doi.org/10.3390/molecules21070861
[55] Sanchez-Maldonado A. F., Schieber A., Gänzle M. G.: Structure-function relationships of the antibacterial activity of phenolic acids and their metabolism by lactic acid bacteria. Journal of Applied Microbiology, 111, 1176-1184 (2011).

https://doi.org/10.1111/j.1365-2672.2011.05141.x

[56] Tweedy B. G.: Inorganic sulfur as a fungicide. in 'Residue reviews' (eds.: Gunther F. A., Gunther J. D.) Springer, New York, Vol. 78, 43-64 (1981). https://doi.org/10.1007/978-1-4612-5910-7 3

[57] Shakhatreh M. A., Al-Smadi M. L., Khabour O. F., Shuaibu F. A., Hussein E. I., Alzoubi K. H.: Study of the antibacterial and antifungal activities of synthetic benzyl bromides, ketones, and corresponding chalcone derivatives. Drug Design, Development and Therapy, 10, 3653-3660 (2016).

https://doi.org/10.2147/DDDT.S116312 